\title{
Analysis and Optimization of Tirana Distribution Network
}

\author{
Marjela Qemali \\ Marialis Çelo \\ Raimonda Bualoti \\ Gurali Hana \\ Polytechnic University - Tirana, Electrical Engineering Faculty \\ Email:m_qemali@yahoo.com
}

Doi:10.5901/ajis.2015.v4n2s2p316

\section{Abstract}

In distribution networks can be easily observed an increase of "sensitive loads" and a gradual increase in power demand. In such a situation emerges the need to increase secure operation on distribution networks. By reconfiguration techniques a more efficient usage of the distribution network can be achieved. Tirana distribution network is the paper focus, with a high level of interest to be studied because represents a significant part of country's consumption. In recent years the main attention in the Albanian distribution network has been focused on the non-technical losses reduction sidelining his need for distribution network optimization. The aim of this work is the analysis of Tirana distribution network by highlighting the need for its optimization. Analysis is performed through the NEPLAN software and through its modules "Optimal Separation Point" and "Load Flow". The obtained results constitute very useful information for distribution network operators.

Keywords: distribution network, optimal separation point, load flow, optimization

\section{Introduction}

A group of interconnected radial circuits form distribution systems. Lower short circuit current and simpler switching and protecting equipment represent the advantages of radial distribution networks. While, lower reliability is present in the radial structure. Hence, distribution systems are planned and built as weakly meshed networks, but operated as radial networks in order to utilize the benefits and to overcome the difficulties. This proces is realized by manual or automatic change of network configuration.

As a criterion to be fulfilled is the fact that radiality of the network is maintained and all the loads are energized. Greater effects and reconfiguration possibilities could be obtained if the network have a large number of switches. In order to achieve usual goals as the reduction of power loss, load balancing or voltage stability, traditionally, network reconfiguration has been implemented but their effects have not been accounted in the evaluation of the system reliability indices (Ji-Yuan Fan, Lan Zhang and John D McDonald 1996).

The main aim of this paper is to present a methodology for network reconfiguration with the objective of finding the optimal configuration that minimizes losses and also improves reliability.

There is a very high penetration in distribution system in many countries of automated technologies due to very low market price and highly reliable technologies applied (V Krishna Rao, J V Pandurangam \& Dr C Radha Krishna 1996). The main advantages of such applications are related with the high quality of the service offered to customers and their respective costs. By performing the operation of network reconfiguration with remotely controllable tie-switches and according to the load profile the network can be operated with minimum power losses.

Distribution networks usually have meshes, but they are radials operated. In the normal operation condition, network losses, bus voltages, loading of the elements are subject of changes through different topology of the network which is realized by selecting different separation points. In case of an element failure, some part of the system may be out of service and can be resupplied by changing also the separation points.

The Optimal Separation Point in distribution system is a problem with multiple objectives. As a first needed step is to select one of the objectives as the objective function and the others as the system constrains. The structure and the assets of distribution system, new markets and new customer service requirements, and the level of its remote control 
have impact on the selection of the objective function. The Optimal Separation Point approaches are briefly described in this section (Neplan 2015).

The goal of this procedure is to eliminate all network meshes by changing the network topology. Usually, there are a considerable number of possible topology configurations. This procedure chooses one topology that minimize/maximize the objective function, considering the constraints and without creating isolated sub-systems.

In (R.Bualoti, M.Qemali, N.Hobdari \&M.Çelo, 2010) are presented some important aspects related to Optimal Separation Point in distribution network and a critical evaluation of Optimal Separation Point Approach. The effectiveness of the analyzed methods is demonstrated through numerical studies in test systems. In this paper we will continue this work for Tirana distribution network which is operating on high power losses and low voltage ranges.

\section{Albanian Distribution Network Situation}

Albanian distribution network, due to significant lack of investments, the presence of very high non-technical losses, lower billing collection levels and a failed privatization process is under entire restructuring process, focused as well on the management and administration policies. Following an unsuccessful experience of privatization, on 10/27/2014, the company moved again from private to government administration, known as "Distribution Network Operator". The new administration board with the political support improved the performance of the company. The first action taken by the management staff of the distribution network, with a significant and sensitive impact to the Distribution Company and customers as well, was the cut of the illegal connections and the legal sanctions for the unpaid bills. The action was accompanied by a series of other measures such as the possibility for the customer to pay the debt created in the past years according to a defined schedule extended in a limited period of time, sensibilization campaign, and possibilities for reducing the amount of the cumulative interes rate for the delayed payment of the past years etc. The situation changes drastically and was reflected in a considerable reduction of non-technical losses, improve of financial portfolio of the company, and increased also of the reliability of the energy supply of the country.

The data reported by the company (OSHEE, 2014) show a level of network losses for 2014 in the amount of $37.81 \%$ versus $45.04 \%$ in 2013 , Figure 1 . Also significantly increased the level of billings collection, resulting in $91.9 \%$ for 2014.

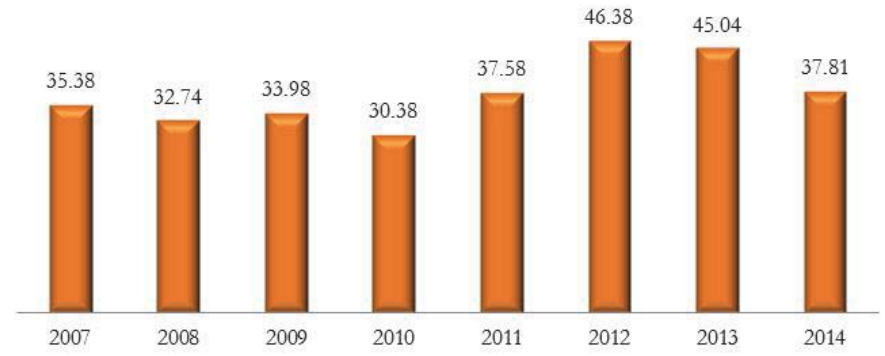

Figure 1: Distribution Network Annual Losses 2007-2014(\%)

These measures contributed to the reduction of distribution losses (non-technical losses) and increased the billing collection (M.Çelo, E.Zeqo \& R.Bualoti 2011). By comparison of energy losses on March for the past three years it is evident that losses have decreased by 15.4\% (from 2013 to 2015). (OSHEE, 2015). These data show a positive development in the OSHEE activity, which are reflected in the other power market participants.

OSHEE is organized in 10 distribution zones and 40 agencies. Tirana distribution network occupies the majority of the Power Consumption Specific Weight, respectively $34.59 \%$ (ERE, 2014). While $10.99 \%$ of the total supplied energy is lost. The study of Tirana distribution network is of high interest because represents a considerable part of the consumption (more than $34 \%$ of the total consumption). It has been characterized by high losses levels with low billing and low collection of money.

The administrative measures within a very short time of implementation have given significant effect to Tirana distribution network with reduction of non-technical losses, growth of billing collection and the reduction of maximum abnormal consumption, as it is shown in Table 1, Table 2(OSHEE, 2015). 
Table 1: Energy Balance for Tirana Distribution Network

\begin{tabular}{|lcccc|}
\hline & $\begin{array}{c}2014 \\
(\mathbf{W W h})\end{array}$ & $\begin{array}{c}2015 \\
(\mathbf{k W h})\end{array}$ & $\begin{array}{c}\text { Balance } \\
(\mathbf{k W h})\end{array}$ & $\begin{array}{c}\text { Balance } \\
(\%)\end{array}$ \\
\hline January & 348.682 .409 & 339.425 .593 & 9.256 .816 & 2.7 \\
\hline February & 305.335 .279 & 291.748 .721 & 11.606 .558 & 3.83 \\
\hline March & 307.352 .316 & 286.384 .401 & 20.968 .275 & 6.83 \\
\hline April & 271.444 .663 & 242.925 .713 & 28.498 .950 & 10.5 \\
\hline
\end{tabular}

Table 2: Energy Losses for Albania Distribution Network

\begin{tabular}{|cccc|}
\hline & 2013 & 2014 & 2015 \\
& $(\%)$ & $(\%)$ & $(\%)$ \\
\hline April & 39.7 & 35.69 & 30.54 \\
\hline
\end{tabular}

Following the action and first measures, the technical losses have been more evident and clear. A lot of investments are necessary and their implementation needs many years for realization due to limited capacity of resources. An accurate knowledge of the Tirana Distribution Company, network topography, all infrastructure elements with the aim of improving the reliability and quality of power supply and optimizing the cost in long terms is crucial.

The aim of this study is focused on the analyze of the actual situation and the possible optimization of Tirana distribution network in order to improve the power quality indicators. Node voltages, elements loading, active and reactive power losses are the power quality indicators evaluated for the maximal operating regime of 2014. Analysis calculations are performed by NEPLAN applicative software owned by the Power System Department of the Faculty of Electrical Engineering at the Polytechnic University of Tirana (Neplan 2015). Tirana distribution network scheme and data were provided by the distribution network operator.

\section{Optimal Separation Point Formulation}

The optimization procedure is realized though optimal separation point module of NEPLAN applicative software. At the beginning of the procedure, all switchable elements of the considered voltage level are switched on. After that, an iterative process follows and the iteration continues until there is no switchable element or element that is not yet worked off left. The main steps to be followed that define the set of possible topologies of the network are listed below (Neplan 2015):

1. Load flow calculation

2. Determination of the element with the lowest apparent power from the all the switchable elements and elements that are not yet worked off

3. The found element is switched off.

4. If the system contains an isolated part or if any constraint is violated, the element is switched on again and is marked as worked off.

The determination of Optimal Separation Point of the distribution networks can be done in many ways. The methods distinguish from each other in terms of the objective function considering technical and economical aspects.

Among the various Optimal Separation Point Approaches, we evaluate the optimization problem containing the following Objective Functions:

1. Losses minimization (LM)

2. Minimize loadings (ML)

3. Minimization number of overloads (MNO)

4. Maximize voltage (MV)

The following constraints:

- Maximum element loadings

- Node voltage limits

- Set of non-switchable elements

In the following we will describe shortly the different approaches. 


\subsection{Losses minimization (LM)}

Technical losses are divided into load losses and no-load losses. Load losses are a function of current and no-load losses are a function of voltage. While the unload losses are also nearly constant, the load losses are not constant and vary according to the equipment loading. They consist of heat losses in the conductors caused by the load current.

The objective function is the minimization of load losses equations:

$$
\min P_{L}=\min \left[\frac{1}{2} \sum_{i=1}^{n} \sum_{j=1}^{n} R_{i j}\left(I_{i} I_{j}^{*}+I_{j} I_{i}^{*}\right)\right]
$$

With the following constraints:

$$
\left.\begin{array}{l}
U_{\min } \leq|U| \leq U_{\max } \\
|I| \% \leq I_{\max } \\
N_{n o s w} \text {-Set of non - switchable elements }
\end{array}\right\}
$$

\subsection{Minimize loadings(ML)}

The load factor $\mathrm{Fd}$ is the ratio of average load $\mathrm{S}$ to the peak load Smax during a specific period $T$. It is assumed that the power factor $\cos (\varphi)$ of the loads is constant. The transmitted power $S$ is proportional to the load current $l_{\text {load. }}$

$$
F_{d}=\frac{\int_{0}^{T} S \cdot d t}{T \cdot S_{\max }}
$$

or

$$
F_{d}=\frac{\int_{0}^{T} I_{\text {load }} \cdot d t}{T \cdot\left[I_{\text {load }}\left(P_{\max }\right)\right]}
$$

The objective function is the minimization of load factor vector module:

$$
\min \left|F_{d}\right|=\left[\begin{array}{c}
F_{d 1} \\
F_{d 2} \\
\vdots \\
F_{d n}
\end{array}\right]
$$

The constraints are the same as expressed in (2).

\subsection{Minimize number of overloads (MNO)}

The overloads elements are characterized by the load factor $F_{d} \geq 1$. The objective function is the minimization of number of overloads elements:

$$
\min N_{F d \geq 1}
$$

The constraints are the same as expressed in (2).

\subsection{Maximize voltage (MV)}

The objective function is the maximization of voltage vector module:

$$
\max |U|=\left[\begin{array}{c}
U_{1} \\
U_{2} \\
\vdots \\
U_{n}
\end{array}\right]
$$

The constraints are the same as expressed in (2).

The selection of the objective function depends from the structure of distribution system and the level of its remote control. So, if the level of remote control is lower, the objective function is selected to give "the minimal number of switching operations". If the companies want to improve the quality of electricity supply "the maximization of voltage" has to be selected. 
In the next section these optimal separation point approaches are examined by applying to two networks.

\section{Case Study: Tirana Distribution Network Analysis}

\subsection{Tirana Distribution Network}

The impact of the presented method is realized for a local network, Tirana distribution network where different medium voltage levels are present 115, 37, 20, 10, 6 kV. Each voltage level is represented through different colours: 115-grey, 37kV-pea-green, $20 \mathrm{kv}$-pink, and 6.3kV-green.

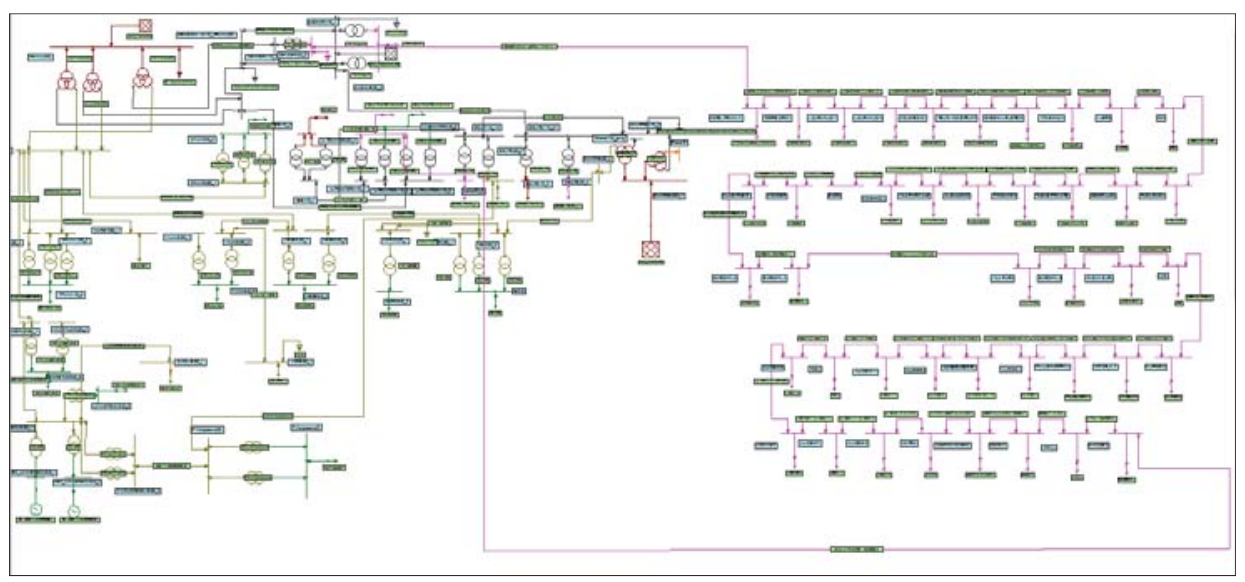

Figure 2: Tirana Distribution Network

Figure 2 represents only a part of Tirana distribution network. In the optimization process only one meshed network in the medium voltage $20 \mathrm{kV}$ is calculated, respectively L1 and C1 feeder. Load power is about $\mathrm{S}_{\text {load }}=345.243+j 98.828$ [MVA].

Many difficulties were encountered during load modelling on Neplan software. The lack of accurate classification of energy consumers according to their profile (household, commercial, lighting and heating services etc.) brought difficulties in determining the exact values of active and reactive power in each distribution substation. This is because in distribution substations are recorded daily value of the consumed energy while Neplan software models load through energy values only by referring to the Velander coefficients.

Based on the data obtained from OSHEE, for each substation was obtained the monthly and yearly recorded value of active and reactive energy. This fact forced us to model the load through the maximal load method. This method calculates the maximum value of active power when annual energy, load factor $(\cos \varphi)$ and velander coefficients are well known values according to the following formula:

$\mathrm{P}_{\max 1}=\mathrm{k}_{1} \cdot \mathrm{E}+\mathrm{k}_{2} \cdot \sqrt{\mathrm{E}}$

Referring to the lack of accurate classification of energy consumers according to their load profile we have done many simulations for different values of Velander coefficients $\mathrm{k}_{1}, \mathrm{k}_{2}$ in order to approximate the results (node voltages, line and transformer loading) obtained from Neplan software simulation with the recorded values from OSHEE.

\subsection{Simulations Results}

\subsubsection{Simulation Results Before Optimization}

In table 3, 4, 5 are presented the results obtained after e load flow calculation for Tirana distribution network before performing the optimization process. These results respond to the maximum regime during 2014. 
Table 3: Network results

\begin{tabular}{|cccc|}
\hline Ploss & Q $_{\text {loss }}$ & Pload & Q Q oad \\
\hline MW & MVAr & MW & MVAr \\
\hline 4.69 & 32.557 & 345.243 & 98.828 \\
\hline
\end{tabular}

Table 4: Overloaded elements

\begin{tabular}{|lc|}
\hline Elements & $\%$ \\
\hline TR3-U.TRAKTORA & 170.78 \\
\hline TR2-TEC & 140.42 \\
\hline AT_SHARRË2 & 124.05 \\
\hline TR220 35 -MEZES & 115.04 \\
\hline TR1 HEC & 114.51 \\
\hline TR2-HEC & 114.51 \\
\hline
\end{tabular}

Table 5: Critical voltages

\begin{tabular}{|lc|}
\hline Nyjet & $\%$ \\
\hline VALIAS(35)_1 & 89.26 \\
\hline VORË(35)_1 & 88.57 \\
\hline IBE(10)_2 & 84.48 \\
\hline U.TRAKTOR(110)_2 & 83.83 \\
\hline IBË(110)_1 & 83.23 \\
\hline
\end{tabular}

The above results indicate the presence of power losses, overloaded elements and voltage levels beyond the allowed limits. These results highlight the need of distribution network optimization which will define the best solution in order to maintain the system parameter within the allowed range.

\subsubsection{Simulation Results after Optimization}

The results obtained from the simulation of different optimization methods are compared with each other in order to come to the conclusion which of the methods has the greatest impact on the network. The compared values are the active and reactive power losses, node voltage, elements loading, aging of equipment, etc. Optimization methods objective, presented at section 3 , consists in determining the optimal separation point in order to achieve the desired objective function. To obtain successfully the objective function the presence of meshed networks is necessary. An L1-C1 feeder, $20 \mathrm{kV}$, represents one of the meshed networks in Tirana distribution network.

\subsubsection{Power Losses Results}

The optimization methods impact on losses minimization is estimated towards reference value of evaluated power losses before optimization, which is considered as 100\%. Figure 3 shows the most affected elements of the $20 \mathrm{kV}$ network. That's why it represents the network voltage range where the optimization is applied. Meanwhile, at $37 \mathrm{kV}$ network voltage range it is evident an increase on power losses and a small losses reduction on $115 \mathrm{kV}$. The largest reduction on power losses is noticed on 20kV distribution network when Minimize Number of Overloads (MNO) and Maximize Voltage (MV) optimization method is applied, respectively in the range of $33.4 \%$ for active power and $34.29 \%$ of reactive power.

During the simulating of the Losses Minimization (LM) and Minimize Loadings (ML) method for the 20kV distribution network, reduction of losses is evaluated in a smaller range, $13.3 \%$ and $14.28 \%$ respectively active and reactive power losses for LM, whereas $28.8 \%$ and $28.57 \%$ respectively active and reactive power losses for ML. 


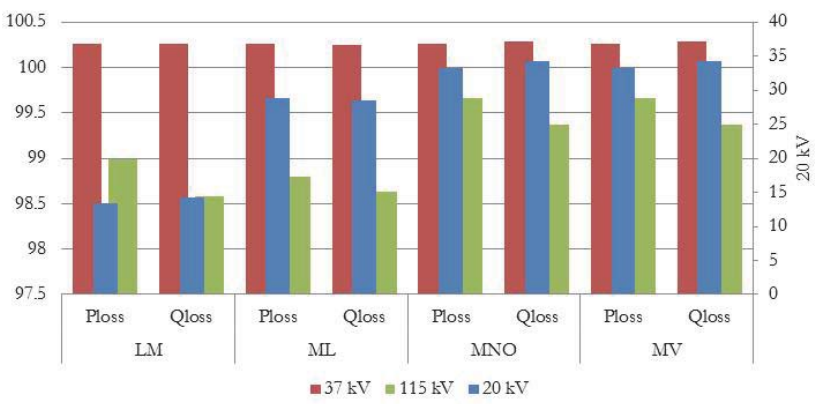

Figure 3: Power losses results after optimization process

\subsubsection{Lines and Transformers Loading}

Table 4 represents the elements loading before optimization. We can see the necessity of loading reduction, both on power lines and transformers. The simulated results presented in Figure 4 show that the optimization methods do not affect the lines loading.

$$
\text { =Loading } \| \text { Loading_LM }=\text { Loading_MV } \| \text { Loading_MNO } \| \text { Loading_ML }
$$

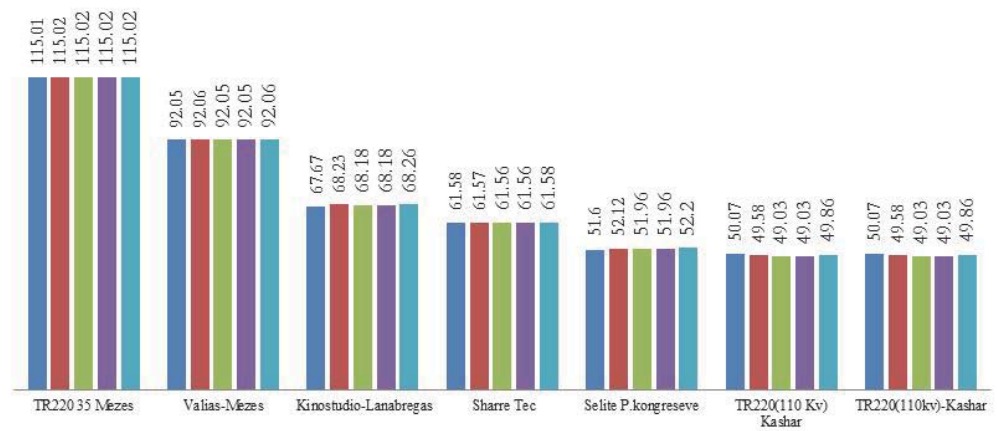

Figure 4: Line loading after optimization process

From lines loading analyzing for each of four optimization methods can be noticed that $\operatorname{Tr} 220(35)$ - Mëzez line remains overloaded and is not affected from none of the methods.

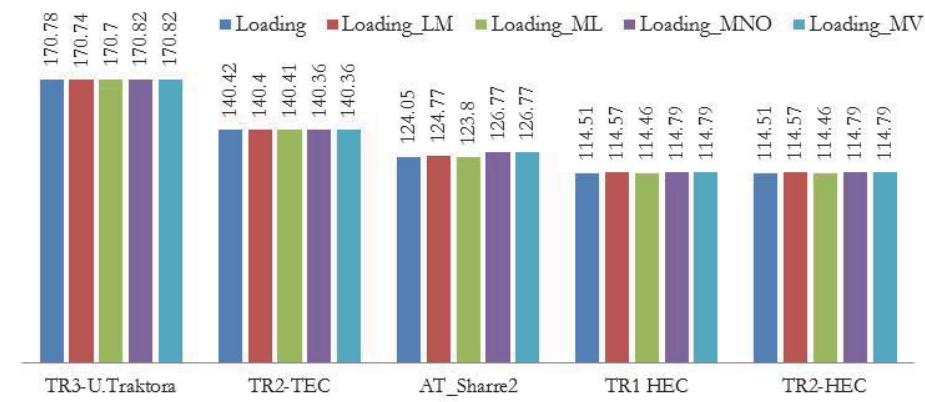

Figure 5: Transformer loading after optimization process 
The same situation is noticed for the transformers. The optimization methods do not affect the overloaded network transformers. Such situations, where parameters of the network elements are immune from the optimization methods, suggest the necessity of new investments to improve the distribution network indicators.

\subsubsection{Node Voltages}

The distribution network critical nodes are those who exceed the upper and lower voltage limits. For distribution network acceptable voltage limits are $\pm 10 \%$. From table 5 can be seen that a considerable number of nodes have exceeded their lower voltage limit which shows again the presence of overloaded elements and the need of Tirana distribution network optimization.

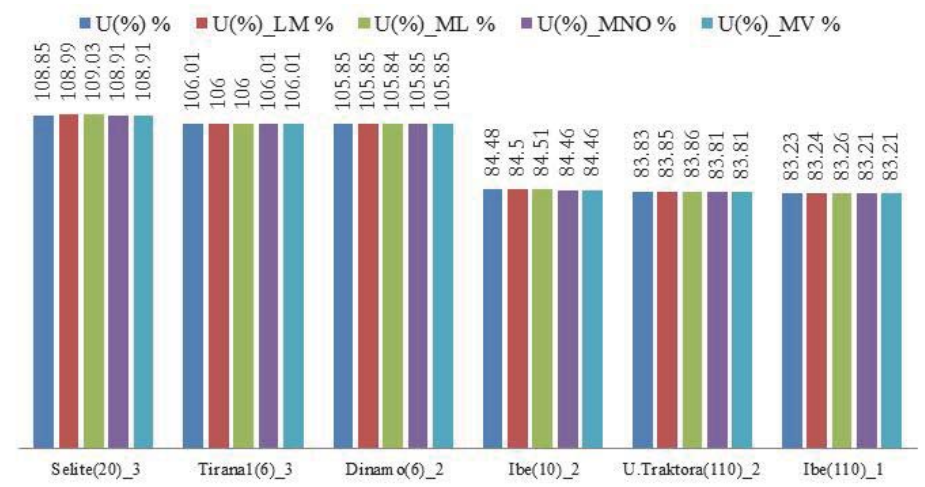

Figure 6: Distribution network critical nodes [\%]

It is shown that although the distribution network is subject to optimization for different objective functions, the node voltages do not fulfil the range of allowed voltage limits. For different objective functions the change in voltage levels is not considerable.

\subsubsection{Distribution Assets Age}

The life time of distribution network elements such as lines and transformers under the provision of regular periodical maintenance and normal operation condition is estimated between 35 to 50 years. In distribution lines the average rate of amortization is about $2.1 \%$ per year.

The high degree of the deterioration of distribution assets is mainly due to their ages, ( between 40 to 50 years old) old technology used, lack of investment in the past, missing of periodical maintenance (such as lines insulators damaged or ruin, aging of transformer oil with loosing of dielectric parameters, missing of periodical treatment of transformer oil).

In Table 6 are listed all the distribution lines with the corresponding information according their years of construction. In the first column are listed the lines constructed more than 40 years old while in the second column those with less than 40 years old.

Referring to the non optimistic results obtained after optimization process according lines loading as well as to the information obtained from Tirana distribution network for the lifetime of elements, it can be identified those lines which have passed the age of their optimal operation. Valias-Mezez, Kinostudio-Lanabregas, Tr220-Kashar are listed from the calculations as overloaded lines and the impact of optimization methods is very low on decreasing of loading. The above mentioned lines are listed in table 4 as elements constructed since more than 40 years in the past. 
Table 6: Construction year of Tirana distribution lines

\begin{tabular}{|llll|}
\hline Lines & Year & Lines & Year \\
\hline Tec-Ndroq & 1980 & T.Tasho2-Al Building & 2008 \\
\hline Qender 20 Kv - Hotel Tirana2 & 1978 & Al.Building - Vila Park Alab & 2008 \\
\hline Vila Park Alb-T.Tashko 1 & 1976 & Hotel Tirana 2 - Torre Drini & 2000 \\
\hline K.Lirise 3 -Miti Deja & 1976 & Ëonder -M.Jashtme C & 2000 \\
\hline Dedejt - Mirali & 1976 & Maternitetio I Ri-K,Lirise 2 & 2000 \\
\hline Valias - Vore & 1975 & Tr220 (110 Kv) - Qender & 1999 \\
\hline T.Drini -L.Gurakuqi 1 & 1975 & Selite-Sharre & 1999 \\
\hline L.Gurakuqi 1- L.Gur.. 2 & 1973 & Sharre- TeC & 1999 \\
\hline TR220 (110kv)- KASHAR & 1972 & MIRALI - SHKOZE 3 & 1998 \\
\hline Kashar Tr 110 -Selite & 1972 & TEUTA KONS -SH.A RUSTEMI & 1993 \\
\hline Tr220 (110 Kv)- Kashar & 1971 & Fadil Rada- Beqir Luga & 1993 \\
\hline T220 (110) - U.Traktora & 1971 & Bardhyl 5-Bardhyl 4 & 1993 \\
\hline TR220 (35 Kv) TR1 -(2) & 1971 & K.LIRISE 4 -MATERNITETI RI & 1993 \\
\hline TR220 (35 Kv) TR1 - (1) & 1971 & K.LIRISE 2 -ALI DEMI 11 & 1993 \\
\hline Valias Mezes & 1971 & Matrix - Ndertim Miniera & 1993 \\
\hline Mezes- Tec & 1968 & Ali Demi 6-4 Gryket & 1993 \\
\hline U.Traktora - Ibe & 1964 & Ali Demi 7 - Ali Demi 2 & 1993 \\
\hline U.Traktori-Selite & 1964 & Uzina U.Traktori - Shkoze 3 & 1993 \\
\hline Lanabregas Q.Molle & 1963 & Tr220 35 -Mezes & 1990 \\
\hline Kinostudio -Lanabregas & 1951 & Tr(220) 35 -Dinamo & 1988 \\
\hline
\end{tabular}

\section{Conclusions}

In this paper, through the optimization process, we have introduced and suggested the power quality indicators that can be improved by setting the remote control circuit breakers in order to achieve the objective function.

From the above analysis resulted that the distribution system operator can realize optimal distribution, with remote control of only 6 circuit breakers out of 134 existing.

The result is positive for the distribution system operator in various technical and economic aspects. They can:

- Reduce losses

- Improve the operational eficency

- Improve the quality of power supply

From the analysis results that overloaded elements are those who have been constructed more than 40 years. This suggests the need for new investments, such as their replacement with new distribution lines. The new investments will certainly reflect significant changes in terms of improving the power quality not only during optimization process, but even during normal operation condition.

The method of Losses Minimization is the most appropriate because of the economic aspect. Today the operator in addition to the economic aspects which is related to the costs of purchase and distribution of energy also faces other costs arising from the penalization scheme established from Regulator Body in respect of meeting the requirements for the quality and realibility indecis of power supply. From this point of view, besides the above method, we suggest other optimization methods like:

1. Maximizing Voltage method can be used successfully for automated networks where the customer is very sensitive to voltage levels

2. Minimizing the number of overloaded method can be used more appropriate for distribution networks with very old and aging elements, which will increase the expected lifetime of existing assets.

\section{References}

ERE (2014). ERE Annual Report 2014, http: //www.ere.gov.al

OSHEE (2014). http://www. oshee.gov.al

Bualoti R., Qemali M., Hobdari N. \& Çelo M. (2010). Investigating the Optimal Separation Point Approach for Optimization of Distribution Power System, MEDPOWER 2010, 7th Mediterranean Conference and Exhibition on Power Generation, Transmission, 
Distribution and Energy Conversion, Agia Napa, Cyprus, 7-10 November 2010.

Çelo M., Zeqo E. \& Bualoti R. (2011). The Regulation Model in Albania Power Sector and Implementation of Incentive-Based Regulation Approaches in Tariff Regulation, DEMSEE 2011, 6-th International Workshop on Deregulated Electricity Market Issues in SouthEastern Europe, BLED, SLOVENIA, 21-22 September 2011.

Neplan (2015). http://www.neplan.ch

Ji-Yuan Fan, Lan Zhang \& John D McDonald (1996). 'Distribution Network econfiguration: Single Loop Optimization.' IEEE Transactions on Power Systems, vol II, no 3, August 1996, p 1643. M V Krishna Rao, J V Pandurangam \& Dr C Radha Krishna (1995). Development and Evaluation of a Distribution Automation System for an Indian Utility.' IEEE Transactions on Power Delivery, vol X, no 1, January 1995. 